\title{
Impact of previous insulin therapy on the prognosis of diabetic patients with acute coronary syndromes
}

\author{
Impacto da insulinoterapia prévia no prognóstico dos \\ pacientes diabéticos com síndromes coronárias agudas
}

${ }^{1}$ Cardiology Department, Coimbra University Hospital, Portugal

${ }^{2}$ Medical School, Universidade de Coimbra, Portugal

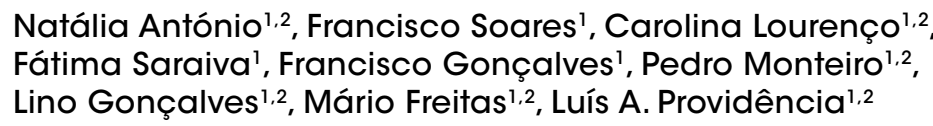

\section{ABSTRACT}

Objective: To determine whether previous insulin treatment independently influences subsequent outcomes in diabetic patients with ACS (acute coronary syndromes). Subjects and methods: 375 diabetic patients with ACS, divided in 2 groups: Group A ( $n=69)$ - previous insulin and Group B ( $n=306)$ - without previous insulin. Predictors of 1-year mortality and major adverse cardiac events (MACE) were analyzed by Cox regression analysis. Results: Group A had more previous stroke $(17.4 \%$ vs. $9.2 \%, p=0.047)$ and peripheral artery disease $(13.0 \%$ vs. $3.6 \%, p=0.005)$. They had significantly higher admission glycemia and lower LDL cholesterol. There were no significant differences in the type of ACS, in 1-year mortality $18.2 \%$ vs. $10.4 \%$, $p=0.103)$ or MACE $(32.1 \%$ vs. $23.0 \%, p=0.146)$ between groups. In multivariate analysis, insulin treatment was neither an independent predictor of 1-year mortality nor of MACE. Conclusion: Despite the more advanced atherosclerotic disease, diabetics under insulin had similar outcomes to those without insulin. Insulin may protect diabetics from the expected poor adverse outcome of an advanced atherosclerotic disease. Arq Bras Endocrinol Metab. 2010;54(7):612-9

Keywords

Insulin; diabetes; acute coronary syndromes; outcomes

\section{RESUMO}

\section{Correspondence to:}

Natália António

Departamento de Cardiologia, Hospital da Universidade de

Coimbra

Praceta Mota Pinto - 3000-075 Coimbra, Portugal

natalia.antonio@gmail.com

Received on Mar/26/2010 Accepted on Aug/31/2010
Objectivo: Avaliar se a insulinoterapia prévia influencia de forma independente o prognóstico de diabéticos após uma síndrome coronária aguda (SCA). Sujeitos e métodos: 375 doentes diabéticos com SCA, divididos em 2 grupos: Grupo $A(n=69)$ - sob insulinoterapia prévia e Grupo $B(n=$ 306) - sem insulinoterapia prévia. Os preditores de mortalidade a um ano e de eventos cardíacos adversos maiores (MACE) foram determinados pela regressão de Cox. Resultados: Verificou-se maior proporção de acidente vascular cerebral prévio $(17,4 \%$ vs. 9,2\%, $p=0,047)$ e doença arterial periférica $(13,0 \%$ vs. 3,6\%, $p=0,005)$ no Grupo A. Esses doentes apresentaram glicemia na admissão significativamente mais elevada e LDL inferior. Não houve diferenças estatisticamente significativas no tipo de SCA, na mortalidade $(18,2 \%$ vs. $10,4 \%, p=0,103)$ e MACE $(32,1 \%$ vs. $23,0 \%, p=0,146$ ) em um ano entre os 2 grupos. Na análise multivariada, a insulinoterapia prévia não foi preditor independente nem de mortalidade, nem de MACE em 1 ano. Conclusão: Apesar da doença aterosclerótica mais avançada, os diabéticos previamente insulino-tratados têm um prognóstico semelhante aos não insulino-tratados. A insulinoterapia crônica poderá proteger os diabéticos da evolução desfavorável própria da doença aterosclerótica avançada. Arq Bras Endocrinol Metab. 2010;54(7):612-9

\section{Descritores}

Insulina; diabetes; síndromes coronárias agudas; prognóstico 


\section{INTRODUCTION}

$\mathrm{D}$ espite significant advances in the treatment of diabetic patients with Acute Coronary Syndromes (ACS), their prognosis remains worse than that of nondiabetics $(1,2)$.

The risk of developing coronary artery disease $(\mathrm{CAD})$ in diabetics is two to four times greater than that of non-diabetics, and diabetics with no history of previous myocardial infarction (MI) have the same risk of future cardiovascular events as non-diabetics who have suffered a previous heart attack $(3,4)$. These results led the "Adult Treatment Panel III of the National Cholesterol Education Program" to establish diabetes mellitus (DM) as a CAD risk equivalent, mandating aggressive anti-atherosclerotic treatment (5).

The metabolic abnormalities caused by DM induce endothelial dysfunction. Among those abnormalities chronic hyperglycemia, dyslipidemia and insulin resistance appear to be the most relevant. The progression of insulin resistance to diabetes parallels the progression of endothelial dysfunction to atherosclerosis (6).

Previous studies have shown that diabetic patients under chronic insulin therapy have a poorer prognosis after percutaneous coronary intervention (PCI) than non-insulin-treated diabetics (7-9). In the context of heart failure, prior insulin therapy also seems to be associated with increased 1-year mortality (10). However, it is unknown whether this represents an effect of insulin itself or the need for insulin is only a marker of a more advanced form of the disease.

Despite the high prevalence of diabetes in ACS patients, there are no studies in the literature addressing the impact of prior insulin therapy on the prognosis of diabetic patients after an ACS.

The main objectives of this work were to compare demographic and clinical characteristics, therapeutic approaches and clinical outcomes after an ACS between diabetics previously treated with insulin and non-insulin-treated diabetics, and to verify whether prior insulin therapy independently influences the prognosis of diabetic patients after an ACS.

\section{SUBJECTS AND METHODS}

\section{Study design}

This is a prospective, observational study (prospective data collection with a retrospective analysis of results) of 375 patients with previously known DM or newly diagnosed DM, consecutively admitted into a single intensive coronary care unit for ACS, between May 2004 and December 2006.

All patients without previously known diabetes underwent an Oral Glucose Tolerance Test (OGTT) on the $4^{\text {th }}$ or $5^{\text {th }}$ day of hospitalization. The diagnosis of new DM was established on the 4 th or 5 th day of hospitalization in patients without previously known diabetes and fasting blood glucose levels equal to or greater than $126 \mathrm{mg} / \mathrm{dL}$, or whose OGTT revealed a blood glucose level equal to or greater than $200 \mathrm{mg} / \mathrm{dL}$ two hours after the administration of 75 grams of glucose (11).

We proceeded to the analysis of a database with standardized records made during the patient's hospitalization, which includes: demographic, clinical, electrocardiographic and laboratorial data, medication (previous, at admission and at discharge), type of ACS, in-hospital complications (including ventricular fibrillation, cardiogenic shock, cardiac arrest, recurrent MI and acute pulmonary edema), length of hospital stay and patient destination after discharge.

These patients underwent a one year follow-up. The occurrence of unplanned revascularization, re-infarction, cerebrovascular accident (CVA) and death from any cause was recorded.

We also analyzed the combined endpoint of cardiovascular death, myocardial nonfatal re-hospitalization for UA or MI and unplanned PCI during the first year - MACE (Major Adverse Cardiac Events).

The study population was divided into two groups according to the previous use (Group A, n = 69) or not (Group B, n = 306) of insulin.

This investigation conforms to the principles outlined in the Declaration of Helsinki, was approved by the Ethical Committee of Clinical Research of the Coimbra University Hospital, and written informed consent was obtained from all patients.

\section{Statistical analysis}

Continuous variables are presented as mean \pm standard deviation (SD). Student's t test or Mann-Whitney test were used for comparison of the two subgroups, according to whether the variables had normal distribution or not, respectively. Categorical variables are expressed as frequencies and percentages and were analyzed by $\chi 2$ test or Fisher's exact test. A p value $<0.05$ was considered statistically significant. 
Multivariate analysis using the Cox regression model was performed to assess the independent effect of prior insulin therapy in the incidence of MACE and mortality at one year. Predetermined (in univariate analysis) or clinically relevant variables were entered into these multivariable regression models. The impact of prior insulin therapy on one-year survival and MACE-free survival was evaluated by Kaplan-Meier analysis.

\section{RESULTS}

\section{General characterization of the study population}

Of the 375 patients included in the study, $252(67.2 \%)$ were male, and the mean age was $70.0 \pm 10.0$ years. Regarding the type of ACS, 55 patients (14.7\%) had Unstable Angina (UA), 205 (54.7\%) non ST segment elevation myocardial infarction (NSTEMI) and $115(30.6 \%)$ ST segment elevation myocardial infarction (STEMI).

Regarding cardiovascular risk factors, $84.8 \%$ of patients had a history of hypertension, $84.7 \%$ hyperlipidemia and $10.2 \%$ had smoking habits. With respect to past medical history, $23.5 \%$ of patients had prior MI, and history of heart failure and of stroke or transient ischemic attack (TIA) was present in $2.5 \%$ and $10.7 \%$, respectively. Newly diagnosed diabetes was found in $30 \%$ of all patients.

Regarding the electrocardiographic and hemodynamic data on admission, $78.0 \%$ of patients presented with Killip class I, $86.1 \%$ were in sinus rhythm (SR) and $11.5 \%$ in atrial fibrillation $(\mathrm{AF})$ in the first electrocardiogram (ECG) performed after hospital admission, and $2.7 \%$ of patients had left bundle branch block (LBBB). The mean blood glucose level at admission was $137.0 \pm 65 \mathrm{mg} / \mathrm{dL}$.

\section{Comparison of previously insulin-treated and non-insulin-treated diabetics}

Concerning the comparison between the two groups, previously insulin-treated diabetics had a higher prevalence of peripheral arterial disease (PAD), previous $\mathrm{MI}$ and prior stroke or TIA (Table 1). Regarding previous cardiovascular treatment, insulin-treated diabetics were more frequently treated with aspirin $(55.1$ vs. $35.6 \%, \mathrm{p}$ $=0.003)$, angiotensin-converting enzyme (ACE) inhibitors ( 55.1 vs. $41.2 \%, \mathrm{p}=0.036), \beta$-blockers (29.0 vs. $18.3 \%, \mathrm{p}=0.046)$, nitrates $(29.0$ vs. $16.3 \%, \mathrm{p}=0.015)$ and diuretics (39.1 vs. 25.5\%, $\mathrm{p}=0.023)$. However, there were no significant differences in the proportion of patients receiving statins between the two groups (36.2 vs. $28.8, \mathrm{p}=0.222$ ). There were $18.8 \%$ patients in the insulin-treated group and $39.9 \%$ in the non-insulin-treated group on oral antidiabetics $(\mathrm{p}=0.001)$.

There were no statistically significant differences regarding the type of ACS between the two groups (Table 1).

Table 1. Comparison of baseline characteristics between diabetics previously under insulin and non-insulin-treated diabetics

\begin{tabular}{lccc}
\hline & $\begin{array}{c}\text { Previous } \\
\text { insulin }\end{array}$ & $\begin{array}{c}\text { No previous } \\
\text { insulin }\end{array}$ & p \\
\hline Total number of patients & 69 & 306 & \\
Demographic data & & & \\
\hline Male gender (\%) & $47 / 69(68.1)$ & $205 / 306(67.0)$ & 0.858 \\
\hline Mean age (years) (SD) & $69.0 \pm 10.0$ & $70.0 \pm 10.0$ & 0.306 \\
\hline Type of ACS (\%) & & & \\
\hline STEMI & $17 / 69(24.6)$ & $98 / 306(32.0)$ & 0.229 \\
\hline NSTEMI & $41 / 69(59.4)$ & $164 / 306(53.6)$ & 0.380 \\
\hline UA & $11 / 69(15.9)$ & $44 / 306(14.4)$ & 0.740 \\
\hline Cardiovascular risk factors & & & \\
\hline Hypertension (\%) & $57 / 67(85.1)$ & $250 / 295(84.7)$ & 0.946 \\
\hline Dyslipidemia (\%) & $57 / 67(85.1)$ & $248 / 293(84.6)$ & 0.929 \\
\hline Smoking (\%) & $6 / 68(8.8)$ & $32 / 306(10.5)$ & 0.687 \\
\hline Stress (\%) & $14 / 68(20.6)$ & $43 / 306(14.1)$ & 0.175 \\
\hline Family History of CAD (\%) & $10 / 68(14.7)$ & $33 / 306(10.8)$ & 0.359 \\
\hline BMl (Kg/m²) & $29.9 \pm 6.9$ & $28.5 \pm 5.0$ & 0.154 \\
Cardiovascular history (\%) & & & \\
\hline Prior myocardial infarction & $22 / 57(38.6)$ & $53 / 262(20.2)$ & 0.003 \\
\hline Prior PCl & $12 / 62(19.4)$ & $33 / 295(11.2)$ & 0.078 \\
\hline CABG & $8 / 67(11.9)$ & $17 / 293(5.8)$ & 0.105 \\
\hline Previous heart failure & $1 / 25(4.0)$ & $3 / 136(2.2)$ & 0.494 \\
\hline Prior stroke & $12 / 69(17.4)$ & $28 / 304(9.2)$ & 0.047 \\
\hline PVD & $9 / 69(13.0)$ & $11 / 304(3.6)$ & 0.005 \\
\hline STEM ST & & & \\
\hline & & & \\
\hline
\end{tabular}

STEMI: ST elevation myocardial infarction; NSTEMI: non-ST elevation myocardial infarction; UA: unstable angina; BMI: body mass index; PCI: percutaneous coronary intervention; CABG: coronary artery bypass graft; PVD: peripheral vascular disease.

For the hemodynamic parameters, the previously insulin-treated diabetics were less often in Killip class I at admission, presented more frequently LBBB and tended to have a lower left ventricular ejection fraction (LVEF) (Table 2).

Concerning laboratory parameters, diabetics in the insulin-treated group had significantly lower total and LDL cholesterol. In these patients we found significantly higher admission glycemia, fasting glycemia and glycosylated hemoglobin (HbAlc), significantly lower levels of hemoglobin and a trend toward worse glomerular filtration rate (GFR - calculated using CockroftGault formula) (Table 2). 
Table 2. Hemodynamic, electrocardiographic and laboratorial data

\begin{tabular}{|c|c|c|c|c|}
\hline & Global population & Previous insulin & No previous insulin & $\mathbf{p}$ \\
\hline \multicolumn{5}{|l|}{ Hemodynamic data } \\
\hline Heart rate, bpm (SD) & $80.0 \pm 16.0$ & $81.0 \pm 18.0$ & $80.0 \pm 16.9$ & 0.569 \\
\hline Systolic blood pressure (mmHg) (SD) & $143.0 \pm 26.0$ & $145.0 \pm 29.0$ & $142.0 \pm 26.0$ & 0.485 \\
\hline Diastolic blood pressure (mmHg) (SD) & $75.0 \pm 14.0$ & $72.0 \pm 14.4$ & $75.0 \pm 14.0$ & 0.101 \\
\hline Killip Class I at admission (\%) & 287/368 (78.0) & $43 / 67(64.2)$ & 244/301 (81.1) & 0.003 \\
\hline Killip Class II at admission (\%) & $70 / 368(19.0)$ & 20/67 (29.9) & $50 / 301(16.6)$ & 0.013 \\
\hline Killip Class III at admission (\%) & $7 / 368(1.9)$ & $3 / 67(4.5)$ & $4 / 301(1.3)$ & 0.117 \\
\hline Killip Class IV at admission (\%) & $4 / 368(1.1)$ & $1 / 67(1.5)$ & $3 / 301(1.0)$ & 0.554 \\
\hline $\operatorname{LVEF}(\%)(S D)$ & $50.0 \pm 11.0$ & $48.0 \pm 12.0$ & $50.0 \pm 11.0$ & 0.145 \\
\hline \multicolumn{5}{|l|}{ Electrocardiographic data (\%) } \\
\hline Synusal rhythm & $321 / 373(86.1)$ & $59 / 69(85.5)$ & 262/304 (86.2) & 0.883 \\
\hline Atrial fibrillation & $43 / 373(11.5)$ & $9 / 69(13.0)$ & $34 / 30(11.2)$ & 0.662 \\
\hline LBBB & $10 / 373(2.7)$ & $5 / 69(7.2)$ & $5 / 304(1.6)$ & 0.022 \\
\hline \multicolumn{5}{|l|}{ Laboratorial parameters } \\
\hline Peak TI ( $\mu \mathrm{g} / \mathrm{L})(\mathrm{SD})$ & $11.0 \pm 29.4$ & $10.5 \pm 28.4$ & $11.1 \pm 30.8$ & 0.764 \\
\hline Peak CK-MB mass $(\mu \mathrm{g} / \mathrm{L})(\mathrm{SD})$ & $36.7 \pm 110.8$ & $36.0 \pm 111.6$ & $37.0 \pm 108.0$ & 0.863 \\
\hline Triglycerides (mg/dL) (SD) & $175.4 \pm 93.0$ & $142.0 \pm 72.0$ & $148.0 \pm 104.0$ & 0.663 \\
\hline Total cholesterol (mg/dL) (SD) & $181.0 \pm 64.0$ & $165.0 \pm 61.0$ & $183.0 \pm 66.0$ & 0.017 \\
\hline LDL cholesterol (mg/dL) (SD) & $124.0 \pm 46.0$ & $108.0 \pm 52.0$ & $126.0 \pm 45.0$ & 0.003 \\
\hline HDL cholesterol (mg/dL) (SD) & $41.0 \pm 11.0$ & $40.0 \pm 10.0$ & $42.0 \pm 11.0$ & 0.230 \\
\hline Apoprotein B (mg/dL) (SD) & $99.0 \pm 35.8$ & $91.0 \pm 38.5$ & $100.0 \pm 35.2$ & 0.077 \\
\hline $\mathrm{GFR}(\mathrm{mL} / \mathrm{min})(\mathrm{SD})$ & $61.7 \pm 21.9$ & $56.8 \pm 23.7$ & $62.8 \pm 21.4$ & 0.083 \\
\hline Admission glycemia (mg/dL) (SD) & $169.0 \pm 73.0$ & $218.0 \pm 108.0$ & $164.0 \pm 64.0$ & $<0.001$ \\
\hline Fasting glycemia (mg/dL) (SD) & $153.0 \pm 58.3$ & $181.0 \pm 92.0$ & $146.0 \pm 51.0$ & $<0.001$ \\
\hline HbA1c (\%) (SD) & $6.5 \pm 2.0$ & $8.1 \pm 2.7$ & $6.4 \pm 1.5$ & 0.007 \\
\hline Baseline hemoglobin (g/dL) (SD) & $13.6 \pm 1.9$ & $13.0 \pm 2.2$ & $13.7 \pm 1.8$ & 0.016 \\
\hline
\end{tabular}

LVEF: left ventricular ejection fraction; LBBB: left bundle-branch block; TI: troponin l; GFR: glomerular filtration rate; HbA1c: glycosylated hemoglobin.

\section{Therapeutic approach}

Patients underwent an invasive strategy in $53.6 \%$ of cases, with PCI in 117 patients (31.2\% of global population). In 72 patients (19.2\% of the total population and $62.6 \%$ of patients with STEMI), primary angioplasty was performed. Of the 201 patients who underwent coronary angiography, 29 (14.4\%) had anatomically normal coronary arteries. Diabetic patients under chronic insulin therapy were less frequently submitted to an early invasive approach compared to patients receiving oral antidiabetics or without any prior antidiabetic therapy $(36.2 \%$ vs. $57.5 \%, \mathrm{p}=0.001)$ (Table 3 ).

Regarding coronary anatomy, diabetic patients under previous insulin therapy showed more often three-vessel disease and left anterior descending artery lesions, but these differences were not statistically significant (Table 3 ).
Concerning medical treatment in the first 24 hours of hospitalization, most patients in the general population were treated with aspirin $(95.7 \%), \beta$-blockers (76.5\%), ACEI (94.1\%), statins (98.1\%) and low molecular weight heparin (LMWH) (97.1\%). In $41.6 \%$ of cases there was the need for diuretics in the first 24 hours of hospitalization. There were no statistically significant differences in the use of these drugs among insulin-treated and non-insulin-treated patients, with the exception of diuretics, which were used more frequently in the insulin-treated group ( $59.4 \%$ vs. $37.6 \%$, $\mathrm{p}=0.001)$.

At the time of hospital discharge, the most prescribed drugs were, in descending order, statins $(95.5 \%)$, ACE inhibitors (89.1\%), aspirin (87.7\%) and $\beta$-blockers $(76.5 \%)$, with no statistically significant differences between the two groups. 
Table 3. Catherization lab data

\begin{tabular}{lcccc}
\hline & Global population & Previous insulin & No previous insulin & p \\
\hline Catheterization during hospitalization (\%) & $201 / 375(53.6)$ & $25 / 69(36.2)$ & $176 / 306(57.5)$ & 0.001 \\
Normal coronaries (\%) & $29 / 201(14.4)$ & $1 / 25(4.0)$ & $28 / 176(15.9)$ & 0.137 \\
3-vessel disease (\%) & $62 / 201(30.8)$ & $9 / 25(36.0)$ & $53 / 176(30.1)$ & 0.551 \\
2-vessel disease (\%) & $39 / 201(19.4)$ & $4 / 25(16.0)$ & $35 / 176(19.9)$ & 0.791 \\
1-vessel disease (\%) & $68 / 201(33.8)$ & $11 / 25(44.0)$ & $57 / 176(32.4)$ & 0.251 \\
Left main disease (\%) & $9 / 201(4.5)$ & $0 / 25(0.0)$ & $9 / 176(5.1)$ & 0.605 \\
LAD disease (\%) & $134 / 201(66.7)$ & $20 / 25(80.0)$ & $114 / 176(64.8)$ & 0.131 \\
Complete revascularization (\%) & $73 / 172(42.4)$ & $10 / 24(41.7)$ & $63 / 148(42.6)$ & 0.934 \\
Non-revascularizable (\%) & $55 / 172(32)$ & $8 / 24(33.3)$ & $47 / 148(31.8)$ & 0.878 \\
\hline
\end{tabular}

LAD: left anterior descending coronary artery.

\section{In-hospital outcomes}

The mean hospital length of stay was $6.0 \pm 3.0$ days with no statistically significant differences between the two groups $(5.0 \pm 3.0$ days in the insulin-treated $v s .6 .0$ \pm 3.0 days in the non-insulin-treated group, $\mathrm{p}=0.700$ ).

The pre-specified in-hospital complications rate was $7.9 \%$ and the in-hospital mortality rate $6.4 \%$. There was no statistically significant differences in in-hospital complications or in-hospital mortality rates among insulintreated and non-insulin-treated patients ( $10.1 \%$ vs. $7.3 \%$, $\mathrm{p}=0.360$ and $10.1 \%$ vs. $5.6 \%, \mathrm{p}=0.174$, respectively).

\section{Post-discharge outcomes - 1 year follow-up}

The overall 1-year mortality rate was $11.7 \%$ and that of MACE $24.5 \%$, without statistically significant differences between the two groups ( $18.2 \%$ vs. $10.4 \%, \mathrm{p}=0.103$ and $32.1 \%$ vs. $23.0 \%, \mathrm{p}=0.146$, respectively). The survival curves showed similar evolution of the two diabetic groups during the 1-year follow-up (Figures 1 and 2).

In the Cox regression, the independent predictors of overall l-year mortality were Killip class on admission $>$ I, total cholesterol $>230 \mathrm{mg} / \mathrm{dL}$ and heart rate on admission $>101 \mathrm{bpm}$ (Table 4$)$.

Regarding independent predictors of MACE occurrence during the first year after the ACS, the multivariate analysis identified the following predictors: $\mathrm{LDL}$ cholesterol $>113 \mathrm{mg} / \mathrm{dL}$, total cholesterol $>180 \mathrm{mg} / \mathrm{dL}$ and GFR $<64 \mathrm{~mL} / \mathrm{min}$. By contrast, female gender was associated with a reduction of $64 \%$ in relative risk of 1-year MACE (Table 5).

Prior insulin therapy was not found to be neither an independent predictor of overall mortality nor of MACE, over one year.

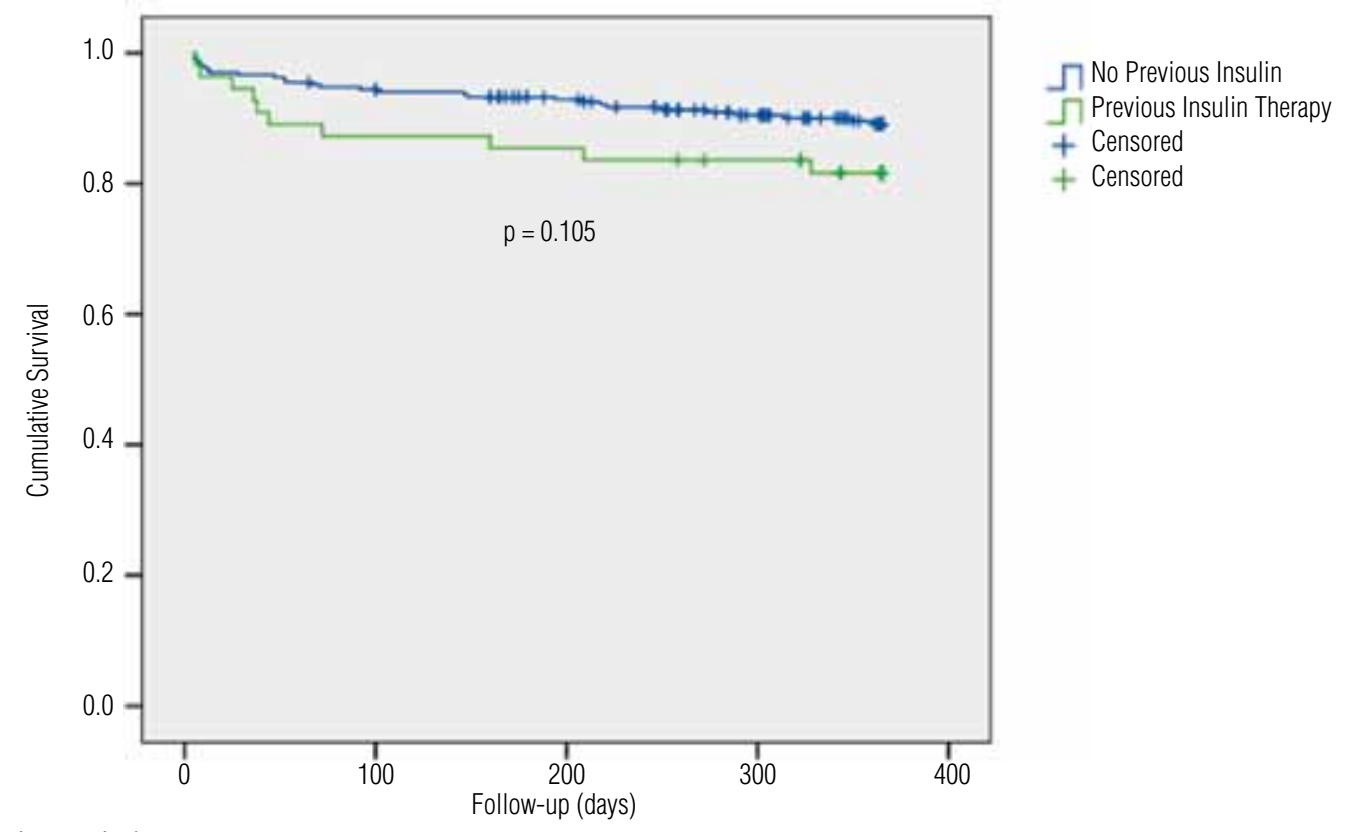

Figure 1. Cumulative survival curves. 


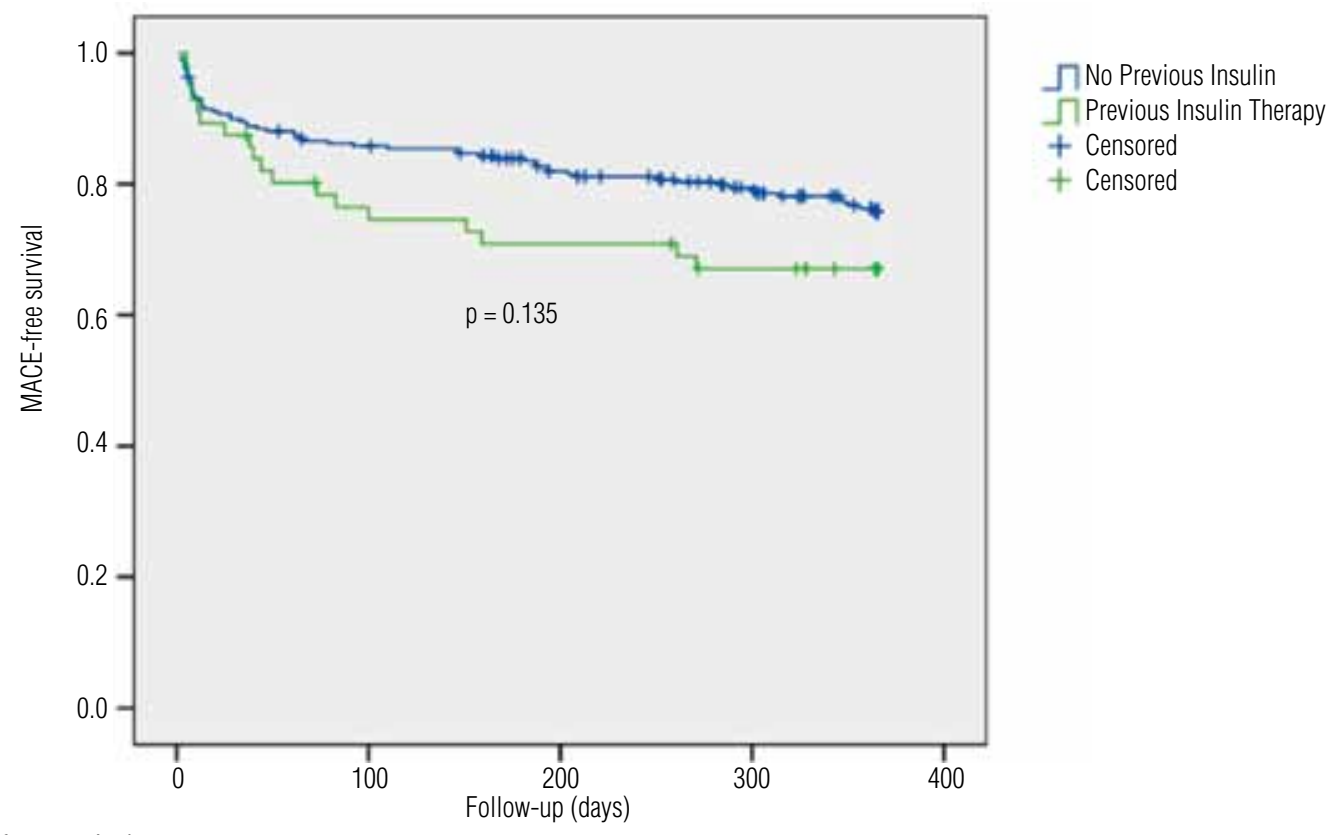

Figure 2. MACE-free survival curves.

Table 4. Independent predictors of 1-year mortality

\begin{tabular}{lccc}
\hline & HR & Cl 95\% & p \\
\hline HR > 101 bpm & 9.24 & $3.76-22.70$ & $<0.001$ \\
Killip class on admission $>$ I & 3.71 & $1.69-8.14$ & 0.001 \\
Total cholesterol $>230 \mathrm{mg} / \mathrm{dL}$ & 3.45 & $1.53-7.75$ & 0.003 \\
Previous insulin therapy & 1.75 & $0.69-4.42$ & 0.235 \\
\hline
\end{tabular}

HR: heart rate; bpm: beats per minute.

Table 5. Independent predictors of MACE during the first year after the ACS

\begin{tabular}{lccc}
\hline & HR & Cl 95\% & p \\
\hline LDL cholesterol $>113 \mathrm{mg} / \mathrm{dL}$ & 2.36 & $1.27-4.38$ & 0.007 \\
GFR $<64 \mathrm{~mL} / \mathrm{min}$ & 2.02 & $1.18-3.48$ & 0.011 \\
Total cholesterol $>180 \mathrm{mg} / \mathrm{dL}$ & 1.83 & $1.05-3.20$ & 0.034 \\
Female gender & 0.36 & $0.19-0.70$ & 0.003 \\
Previous insulin therapy & 1.64 & $0.86-3.10$ & 0.132 \\
Age $>80$ years & 2.04 & $0.98-4.24$ & 0.057 \\
\hline
\end{tabular}

ACS: acute coronary syndrome; GFR: glomerular filtration rate.

\section{DISCUSSION}

After an ACS, diabetic patients have a considerably poorer prognosis in the short and long term than their non-diabetic counterparts $(3,4,12)$. The "Euro Heart Survey on Diabetes and the Heart" showed that either previously known DM or newly diagnosed DM are associated with a particularly high risk of death and cardiovascular events during the first year of clinical follow-up (13). On the other hand, hyperglycemia on admission has been associated with decreased survival after an ACS, either in diabetics or non-diabetics $(14,15)$. Recently, it has been demonstrated that persistent hyperglycemia during hospitalization for ACS was a better predictor of in-hospital mortality than admission glycemia (16). However, is not completely clear whether this decreased survival is related to the development of hyperglycemia in response to stress or whether it is related to a worse prior metabolic control $(15,17)$.

Besides the well-known benefit of insulin in the metabolic control of diabetic patients, some researchers also propose the existence of a cardioprotective action. Recent studies have shown that insulin exerts anti-inflammatory and anti-atherogenic effects and improves endothelial function (18-21).

In the past decade it has become evident that the endothelium is not a simple barrier. Nowadays, the endothelium is viewed as a complex organ, with autocrine and paracrine function, constituting a first line physiological defense against atherosclerosis (6).

The metabolic abnormalities of diabetes are associated with endothelial dysfunction. Diabetes induces oxidative and inflammatory stress, vasoconstrictor responses, thrombotic phenomena and pro-apoptotic effects on endothelial cells (22). 
Insulin appears to exert multiple beneficial effects on endothelial cells, platelet and leukocyte function, which could be potentially cardioprotective and antiatherosclerotic (23-25).

Several mechanisms have been proposed to explain the beneficial effect of insulin on endothelial function: 1) reduction of serum glucose, triglycerides and free fatty acids (which have been associated with endothelial dysfunction) $(26,27), 2)$ endothelium-independent vasodilatation (which seems to increase significantly with insulin therapy), 3) reduction of oxidative stress (28), 4) stimulation of nitric oxide production in endothelial cells (29) and 5) stimulation of endothelial progenitor cells via the activation of the receptor for insulin growth factor type 1 (IGF-1). In turn, endothelial progenitor cells have the ability to improve function of injured vessels by stimulating re-endothelialization and neovascularization (29).

However, there are some studies that suggest opposite effects, stating that insulin therapy is associated with increased vascular resistance, ventricular hypertrophy and endothelial dysfunction $(1,10)$.

In this work it was found that prior insulin therapy did not independently increase the overall mortality or the incidence of major adverse cardiac events in the first year after an ACS.

In our diabetic population there was a high rate of adherence to the pharmacological therapy approach advocated in acute coronary syndromes. In fact, the use of the generality of the drugs recommended in the context of ACS was far superior compared to international multicenter studies $(13,30)$.

An early invasive strategy was used in most patients, but less frequently in diabetics under prior insulin therapy. One possible explanation for this is that some insulin-treated diabetics had previously known severe, diffuse, non-revascularizable CAD.

The fact that there were no statistically significant differences in the type of ACS or in the levels of biochemical markers of myocardial necrosis between the two groups, suggests that prior antidiabetic therapy does not influence the type of ACS or the extent of myocardial necrosis.

The higher prevalence of PAD and of prior stroke/ TIA in the insulin-treated group probably reflects a more advanced form of atherosclerosis, involving multiple arterial territories. However, despite this and the lower use of an invasive strategy, the overall mortality and the occurrence of MACE during the first year after the ACS in insulin-treated patients were similar to that of non-insulin-treated patients. Therefore, prior insulin therapy did not independently increase the overall mortality or the incidence of major adverse cardiac events in the first year after the ACS.

\section{CONCLUSIONS}

This work suggests that the worst prognosis of insulintreated diabetics reported in other studies is not an independent effect of insulin and probably it can be explained by demographic, clinical or therapeutic differences.

Moreover, it is possible that insulin therapy protects diabetic patients from the diabetics patients from the expected poor adverse outcome of an advanced atherosclerotic disease. It would therefore be important to conduct prospective studies to evaluate the effects of insulin on endothelial function, seeking to understand the pathophysiological mechanisms involved and to investigate the real impact of insulin therapy in CAD progression.

\section{Study limitations}

The size of the cohort and the number of clinical events upon which we base our conclusions are, by comparison to the data accumulated in acute coronary syndromes and diabetes, relatively small. However, our cohort was unselected in terms of cardiovascular risk factors, age, gender and treatment and is in fact a real population seen in standard clinical practice.

We recognize that one important limitation of this study is the lack of information about diabetes duration, which may be significantly longer in previously insulin-treated diabetics and could be associated to a more diffuse atherosclerotic disease.

Acknowledgement: Statistical analysis was performed by the $\mathrm{Na}$ tional Center for Data Collection in Cardiology (CNCDC), a body of the Portuguese Society of Cardiology.

Disclosure: no potential conflict of interest relevant to this article was reported.

\section{REFERENCES}

1. Beckman JA, Creager MA, Libby P. Diabetes and atherosclerosis: epidemiology, pathophysiology, and management. JAMA. 2002;287(19):2570-81.

2. Norhammar A, Lindbäck J, Rydén L, et al; Register of Information and Knowledge about Swedish Heart Intensive Care Admission (RIKS-HIA). Improved but still high short- and long-term mortality 
rates after myocardial infarction in patients with diabetes mellitus: a time-trend report from the Swedish Register of Information and Knowledge about Swedish Heart Intensive Care Admission. Heart. 2007;93(12):1577-83.

3. Feskens E, Kromhout D. Glucose tolerance and the risk of cardiovascular disease: the Zutphen Study. J Clin Epidemiol. 1992;45(11):1327-34.

4. Grant PJ. Diabetes mellitus as a prothrombotic condition. J Intern Med. 2007;262:157-72.

5. Expert Panel on Detection, Evaluation, and Treatment of High Blood Cholesterol in Adults. Executive Summary of the Third Report of the National Cholesterol Education Program (NCEP) Expert Panel on Detection, Evaluation, and Treatment of High Blood Cholesterol in Adults (Adult Treatment Panel III). JAMA. 2001;285(19):2486-97.

6. Hadi $\mathrm{H}$, Suwaidi J. Endothelial dysfunction in diabetes mellitus. Vasc Health Risk Manag. 2007;3(6):853-76.

7. RozenmanY, Sapoznikov D, Gotsman M. Restenosis and progression of coronary disease after balloon angioplasty in patients with diabetes mellitus. Clin Cardiol. 2000;23(12):890-4.

8. Stein B, Weintraub WS, Gebhart SP, et al. Influence of diabetes mellitus on early and late outcome after percutaneous transluminal coronary angioplasty. Circulation. 1995;91(4):979-89.

9. Mathew V, Frye RL, Lennon R, et al. Comparison of survival after successful percutaneous coronary intervention of patients with diabetes mellitus receiving insulin versus those receiving only diet and/or oral hypoglycemic agents. Am J Cardiol. 2004;93(4):399-403.

10. Smooke S, Horwich TB, Fonarow GC. Insulin-treated diabetes is associated with a marked increase in mortality in patients with advanced heart failure. Am Heart J. 2005;149(1):168-74.

11. Ryden L, Standl E, Bartnik M, et al; Task Force on Diabetes and Cardiovascular Diseases of the European Society of Cardiology (ESC); European Association for the Study of Diabetes (EASD). Guidelines on diabetes, pre-diabetes, and cardiovascular diseases: executive summary. The Task Force on Diabetes and Cardiovascular Diseases of the European Society of Cardiology (ESC) and of the European Association for the Study of Diabetes (EASD). Eur Heart J. 2007;28(1):88-136.

12. Pitsavos C, Kourlaba G, Panagiotakos DB, et al. Characteristics and in-hospital mortality of diabetics and nondiabetics with an Acute Coronary Syndrome; the GREECS study. Clin Cardiol. 2007;30(5):239-44.

13. Anselmino M, Ohrvik J, Malmberg K, et al; Euro Heart Survey Investigators. Glucose lowering treatment in patients with coronary artery disease is prognostically important not only in established but also in newly detected diabetes mellitus: a report from the Euro Heart Survey on Diabetes and the Heart. Eur Heart J. 2008;29(2):177-84.

14. Malmberg K, Norhammar A, Wedel H, et al. Glycometabolic state at admission: important risk marker of mortality in conventionally treated patients with diabetes mellitus and acute myocardial infarction: long-term results from the Diabetes and Insulin-Glucose Infusion in Acute Myocardial Infarction (DIGAMI) Study. Circulation. 1999;99(20):2626-32.
15. Meier JJ, Deifuss S, Klamann A, Launhardt V, Schmiegel WH, Nauck MA. Plasma glucose at hospital admission and previous metabolic control determine myocardial infarct size and survival in patients with and without type 2 diabetes: the Langendreer Myocardial Infarction and Blood Glucose in Diabetic Patients Assessment (LAMBDA). Diabetes Care. 2005;28(10):2551-3.

16. Kosiborod M, Inzucchi SE, Krumholz HM, Xiao L, Jones PG, Fiske $\mathrm{S}$, et al. Glucometrics in patients hospitalized with acute myocardial infarction: defining the optimal outcomes-based measure of risk. Circulation. 2008;117(8):1018-27.

17. Capes SE, Hunt D, Malmberg K, Gerstein HC. Stress hyperglycaemia and increased risk of death after myocardial infarction in patients with and without diabetes: a systematic overview. Lancet. 2000;355(9206):773-8.

18. Vehkavaara S, Yki-Järvinen H. 3.5 years of insulin therapy with insulin glargine improves in vivo endothelial function in type 2 diabetes. ArteriosclerThromb Vasc Biol. 2004;24(2):325-30.

19. Dandona P, Chaudhuri A, Mohanty P, Ghanim H. Anti-inflammatory effects of insulin. Curr Opin Clin Nutr Metab Care. 2007;10(4):511-7.

20. Rask-Madsen C, Ihlemann N, Krarup T, Christiansen E, Kober L, Kistorp CN, et al. Insulin therapy improves insulin-stimulated endothelial function in patients with type 2 diabetes and ischemic heart disease. Diabetes. 2001;50(11):2611-8.

21. Vehkavaara S, Mäkimattila S, Schlenzka A, Vakkilainen J, Westerbacka J, Yki-Järvinen $\mathrm{H}$. Insulin therapy improves endothelial function in type 2 diabetes. Arterioscler Thromb Vasc Biol. 2000;20(2):545-50.

22. Dandona P, Chaudhuri A, Ghanim H, Mohanty P. Use of insulin to improve glycemic control in diabetes mellitus. Cardiovasc Drugs Ther. 2008;22(3):241-51.

23. De Vriese AS, Verbeuren TJ, Van de Voorde J, Lameire NH, Vanhoutte PM. Endothelial dysfunction in diabetes. Br J Pharmacol 2000;130(5):963-74.

24. Hopfner RL, Gopalakrishnan V. Endothelin: emerging role in diabetic vascular complications. Diabetologia. 1999;42(12):1383-94.

25. Libby P. Current concepts of the pathogenesis of the acute coronary syndromes. Circulation. 2001;104(3):365-72.

26. Taskinen MR, Sane T, Helve E, Karonen SL, Nikkilä EA, Yki-Järvinen $\mathrm{H}$. Bedtime insulin for suppression of overnight free-fatty acid, blood glucose, and glucose production in NIDDM. Diabetes. 1989;38(5):580-8.

27. Williams $S B$, Goldfine $A B$, Timimi FK, et al. Acute hyperglycemia attenuates endothelium-dependent vasodilation in humans in vivo. Circulation. 1998;97(17):1695-701.

28. Tesfamariam B, Cohen RA. Free radicals mediate endothelial cell dysfunction caused by elevated glucose. Am J Physiol. 1992;263(2 Pt 2):H321-6.

29. Cubbon $R$, Rajwani A, Wheatcroft SB. The impact of insulin resistance on endothelial function, progenitor cells and repair. Diab Vasc Dis Res. 2007;4(2):103-11.

30. Fox KA, Goodman SG, Anderson FA Jr, et al; GRACE investigators. From guidelines to clinical practice: the impact of hospital and geographical characteristics on temporal trends in the management of acute coronary syndromes:The Global Registry of Acute Coronary Events (GRACE). Eur Heart J. 2003;24(15):1414-24. 